\title{
ANÁLISIS PROXIMAL \\ Y PERFIL DE AMINOÁCIDOS DEL \\ AISLADO PROTEICO DEL CHOCHO ANDINO \\ ECUATORIANO \\ (FABACEAE: Lupinus mutabilis)
}

\author{
PROXIMAL ANALYSIS AND AMINO ACID PROFILE OF THE \\ ECUADORIAN ANDEAN LUPIN (FABACEAE: Lupinus mutabilis) \\ PROTEIN ISOLATE
}

\section{Daniela Guerra F . \& Pablo Pozo P. ${ }^{2}$}

Recibido: 9 agosto 2017 / Aceptado: 11 diciembre 2017

Palabras claves: aislado proteico, aminoácidos, análisis proximal, Lupinus, nutrición

Keywords: amino acids, Lupinus, nutrition, protein isolate, proximal analysis

\section{RESUMEN}

El propósito de este estudio fue aislar contenido proteico total de los granos de chocho (Fabaceae: Lupinus mutabilis). El contenido de macronutrientes ha sido evaluado a través de un análisis proximal: proteína total $(67,25 \%)$, carbohidratos $(18,67 \%)$, grasa $(5,95 \%)$, ceniza $(4,12 \%)$ y humedad $(4,01 \%)$. El análisis por cromatografía de capa fina ha demostrado que había siete aminoácidos

1 Pontificia Universidad Católica del Ecuador, Facultad de Ciencias Exactas y Naturales, Escuela de Ciencias Biológicas, Quito, Ecuador (daniela.g.f.90@gmail.com).

2 Pontificia Universidad Católica del Ecuador, Facultad de Ciencias Exactas y Naturales, Escuela de Ciencias Químicas, Quito, Ecuador (pepozo@puce.edu.ec). 
esenciales presentes en el aislado proteico: ácido glutámico, treonina, valina, isoleucina, leucina, metionina y triptófano; además, la presencia de ácido glutámico y de aminoácidos de cadena ramificada.

\section{ABSTRACT}

The purpose of the present study was to isolate the total protein content of lupin beans (Fabaceae: Lupinus mutabilis). The macronutrient content was evaluated through a proximal analysis: total protein (67.25\%), carbohydrates $(18.67 \%)$, fat $(5.95 \%)$, ash $(4.12 \%)$, and moisture $(4.01 \%)$. The thin-layer chromatography analysis showed that seven essential amino acids are present in the protein isolate: glutamic acid, threonine, valine, isoleucine, leucine, methionine, tryptophan and also, the presence of glutamic acid and branched-chain amino acids.

\section{INTRODUCCIÓN}

La diversidad de los cultivos andinos ha permitido que varias culturas y sociedades puedan establecerse. Uno de los cultivos más notorios es el de chocho andino (Lupinus mutabilis: Fabaceae). El género se originó en la región andina de Ecuador, Perú y Bolivia; esta área se caracteriza por la variedad de especies de Lupinus. Se cree que existen 83 especies descubiertas (Jacobsen \& Mujica, 2006).

En Ecuador, la producción y el consumo de chocho se restringe a la Sierra. Las provincias con mayor producción son: Cotopaxi, Cañar y
Chimborazo (Horton, 2014). El chocho andino crece en climas templados a altitudes entre 2500-3600 m. El cultivo es susceptible a enfermedades y plagas; la falta de investigación y conocimiento no permite que la industria de producción de chochos crezca. Se estima que la producción solo cubre el $60 \%$ de la demanda nacional (Jacobsen \& Sherwood, 2002). No obstante, el consumo de chochos ha sido promovido por compañías que venden el grano listo para comer en cadenas de supermercados nacionales (Horton, 2014), esto ha incentivado la investigación cientí- 
fica alrededor de los granos de chocho (Peralta et al., 2012).

En el aspecto nutricional, el chocho se caracteriza por su alto contenido de proteínas $(42,2 \%)$ y su contenido medio de carbohidratos (16\%) (Bermejo \& León, 1994). También por sus micronutrientes: calcio 0,48 \%, fósforo $0,43 \%$, potasio $0,02 \%$, hierro $120 \mathrm{mg} / \mathrm{kg}$, zinc $50 \mathrm{mg} / \mathrm{kg}$ (Villacrés et al., 2006; Jaramillo Galarza, 2005). Dentro de la familia Fabaceae, se encuentran a todas las leguminosas de consumo humano. La soya es la más popular; su alto valor nutricional y versatilidad han permitido que su uso sea mundial. En la industria alimenticia para deportistas, la proteína aislada de soya ha ganado notoriedad. Después que un deportista haya completado un entrenamiento (cardiovascular o fuerza), se crean micro-traumas en el músculo esquelético y el catabolismo de aminoácidos se intensifica (Shimomura et al., 2006). Para reparar las micro-lesiones es necesaria una alimentación apropiada después del ejercicio (Farrell, Joyner \& Caiozzo, 2012). Según el tipo de ejercicio que se ha hecho, la proporción de macronutrientes a ingerir, varía. En actividades que requieran fuerza o re- sistencia, el consumo de alimentos con alto contenido proteico es necesario, como un aislado de proteína. La proteína permite recuperar los aminoácidos perdidos durante el entrenamiento (Farrell et al., 2012). Los aminoácidos que reparan y preservan el músculo son: leucina, isoleucina y valina (Børsheim et al., 2002), su ingesta es primordial para la recuperación y crecimiento muscular. Desafortunadamente, en Ecuador, los suplementos nutricionales para deportistas son de baja producción y la mayoría son importados. Además, estas opciones son limitadas a suplementos de origen animal (derivados lácteos y huevo) y las opciones vegetales se limitan a la soya.

Así mismo, el grano de chocho tiene ventajas sobre el de soya. Por ejemplo, estudios han demostrado que $L$. mutabilis tiene 10,9 \% más proteína que la soya (Jacobsen \& Mujica, 2006). Además, los chochos no han sido sujetos a modificación genética como la soya; hoy en día, por razones de salud y ambientales, los consumidores prefieren evitar alimentos modificado genéticamente (FAO, 2003a). Esto otorga al chocho potencial dentro de la industria alimenticia. 


\section{MATERIALES Y MÉTODOS}

\section{Muestreo}

Se adquirieron granos de chocho hidratados comerciales, todas las muestras provinieron de la fábrica "La Verde", que procesa chochos de la región de Machachi, Ecuador.

\section{Obtención de la harina de chocho}

Se removió la cáscara de los chochos hidratados. Posteriormente, estos fueron secados y molidos usando un molino (AOAC, 2011a).

\section{Obtención de la harina de chocho desgrasada}

Se empleó un sistema de extracción continua (Soxhlet) con hexano como solvente de extracción (Lusas \& Riaz, 1995).

\section{Obtención del aislado proteico}

A partir de la harina desgrasada, la proteína fue solubilizada con una solución de $\mathrm{NaOH} 10$ \% (pH 6,8-10). Se procedió a centrifugar a 4000 rpm durante 5 min y se recuperaron los sólidos. El contenido proteico fue precipitado con una solución de $\mathrm{HCl}$ $10 \%(\mathrm{pH} 4,5)$, se centrifugó a 4000 rpm durante 5 min, el contenido proteico se precipitó como una nata. Esta nata fue neutralizada con una solución de $\mathrm{NaOH} 10 \%(\mathrm{pH}$ 6,5-7). La solución se centrifugó a 4000 rpm durante $5 \mathrm{~min}$ y se recuperó una nata. La nata fue secada durante 24 h en una estufa a $85^{\circ} \mathrm{C}$ (Lusas \& Riaz, 1995).

\section{Análisis proximal del aislado pro- teico}

\section{Contenido total de proteínas}

El contenido de nitrógeno fue determinado usando el método Kjeldahl. La digestión se realizó en un digestor usando tabletas Kjeldahl. La destilación de las muestras se realizó en un destilador automático y la titulación se hizo manualmente con el indicador de Tashiro (AOAC, 2011b).

\section{Contenido total de grasa}

Se empleó un sistema de extracción continua (Soxhlet) a microescala, usando hexano como solvente de extracción (AOAC, 2011c). 


\section{Contenido de cenizas totales}

Las muestras fueron calcinadas en crisoles de porcelana en una mufla a $550{ }^{\circ} \mathrm{C}$ durante $24 \mathrm{~h}$. Los resultados fueron expresados en porcentaje de una relación peso/peso (AOAC, 2011d).

\section{Humedad}

Las muestras fueron secadas en cápsulas de porcelana en una estufa a $130{ }^{\circ} \mathrm{C}$ durante $3 \mathrm{~h}$ Los resultados fueron expresados en porcentaje de una relación peso/peso. (AOAC, 2011a).

\section{Carbohidratos totales}

Se realizó por la diferencia matemática entre la muestra y la sumatoria del contenido de proteína, grasa, ceniza y humedad (FAO, 2003b).

\section{Análisis del contenido de aminoáci- dos por Cromatografía en Capa Fina (CCF)}

\section{Preparación de muestras}

Se tomaron aproximadamente $0,3 \mathrm{~g}$ del aislado proteico y se añadieron a $150 \mathrm{~mL}$ de una solución de $\mathrm{HCl} 3 \mathrm{~N}$.
Otra muestra de $0,3 \mathrm{~g}$ fue colocada en $150 \mathrm{~mL}$ de una solución de $\mathrm{NaOH} 4,2 \mathrm{~N}$. Todas las muestras fueron hidrolizadas a $100{ }^{\circ} \mathrm{C}$ durante 24 h (Kalman, 2014). Después de las 24 $h$, las muestras fueron filtradas antes de ser colocadas en la placa de TLC. Aproximadamente $3 \mu \mathrm{L}$ de la muestra fueron colocados en la línea de base de la placa (placa de celulosa plástica Art. 5577, 20x20 cm, sin indicador de fluorescencia; E.M Reagents) (Staneck, 1974).

\section{Análisis CCF}

La CCF ascendente se realizó en un sistema con solvente de $n$-Butanol, ácido acético glacial y agua destilada (4:1:1) durante $4 \mathrm{~h}$. El cromatograma fue secado al aire y fue revelado con ninhidrina $1 \%$ en acetona y posteriormente secado por 15 min en una estufa a $60^{\circ} \mathrm{C}$ (Haer, 1969). Se utilizó una mezcla de aminoácidos (Amino Acid Calibration Mixture Type 1; Beckman) como estándar para la identificación de la muestra.

\section{Análisis estadístico}

Se utilizó el IBM $®$ SPSS $®$ Statistics Version (IBM, 2012). Los resultados fue- 
ron expresados como promedio, cada coeficiente de variación $(C V)<20 \%$. análisis se repitió hasta obtener un

\section{RESULTADOS}

Análisis proximal del aislado pro- proximal del aislado proteico. El anáteico de chocho lisis demuestra un $67,25 \%$ de proteína, $18,67 \%$ de carbohidratos La Tabla 1 muestra la composición totales y 5,95\% de grasa.

Tabla 1. Análisis proximal del aislado proteico de chocho

\begin{tabular}{lc}
\hline Parámetro & $\begin{array}{c}\text { Aislado Proteico } \\
\text { Chocho }\end{array}$ \\
\hline Proteína \% & $67,25 \pm 5,75$ \\
Grasa \% & $5,95 \pm 1,07$ \\
Ceniza \% & $4,12 \pm 0,27$ \\
Humedad \% & $4,01 \pm 0,29$ \\
Carbohidratos \% & $18,67 \pm 2,63$ \\
\hline
\end{tabular}

Perfil de aminoácidos del aislado proteico de chocho

Varias placas de CCF, con diferentes solventes, se realizaron como prue- teico. bas preliminares para calcular la eficiencia de la separación de las muestras. La Tabla 2 muestra los aminoácidos presentes en el aislado pro- 
Tabla 2. Aminoácidos identificados en el aislado proteico de chocho

\begin{tabular}{lccc}
\hline Aminoácido & Esencial & BCAA & RM \\
\hline Ácido glutámico & $*$ & & \\
Cisteína & & & \\
Treonina & $*$ & & \\
Alanina & & & \\
Valina & $*$ & + & $\square$ \\
Isoleucina & $*$ & + & $\square$ \\
Leucina & $*$ & + & $\square$ \\
Metionina & $*$ & & \\
Triptófano & $*$ & & \\
\hline
\end{tabular}

BCAA: Aminoácidos de cadena ramificada

RM: Recuperación muscular

La Figura 1 muestra el cromatograma de los aminoácidos de cadena ramificada (BCAA por sus siglas en inglés) y ácido glutámico presentes en el aislado. Las muestras estaban muy diluidas y las manchas eran asimétricas y casi imperceptibles, dificultando la cuantificación. Sin embargo, se identificaron 7 aminoácidos esenciales: ácido glutámico, treonina, valina, isoleucina, leucina, metionina y triptófano.

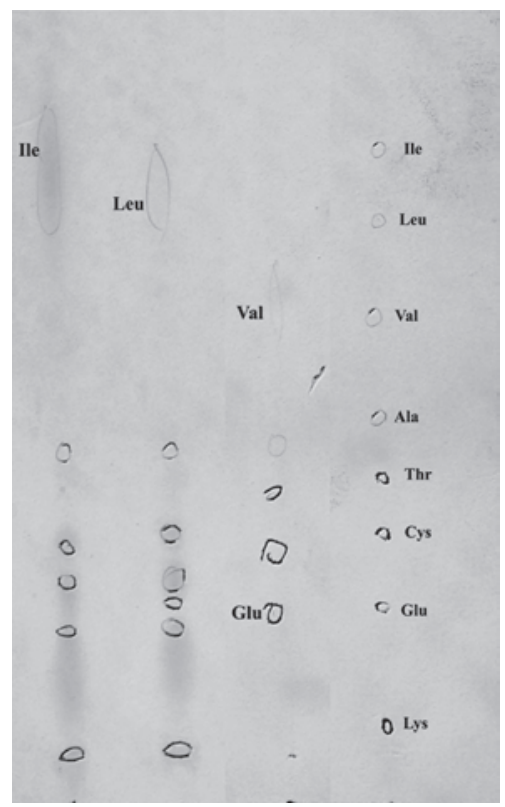

Figura 1. Cromatograma de aminoácidos 


\section{DISCUSIÓN}

Los resultados obtenidos prueban que se logró aislar el contenido proteico de la harina desgrasada. En comparación con aislados proteicos comerciales disponibles (chocho, soya, arveja y suero de leche), podemos observar que la proteína de soya y de suero de leche tienen un mayor contenido proteico - 83,83\% (NOW Foods, 2015) y 83,87 \% (Bluebonnet Nutrition Corporation, 2015) respectivamente, seguido por la arveja (78,94\%) (Growing Naturals, 2015) y el chocho $(67,25 \%)$. El menor contenido proteico del aislado del chocho se puede deber al proceso de aislamiento, porque el protocolo que se utilizó estaba diseñado para soya. A pesar que la soya y el chocho pertenecen a la subfamilia Faboideae, ellos deberían ser procesados de diferente manera por sus distintas características. Por ejemplo, para ser apto para el consumo humano, el chocho debe pasar por un proceso mediante el cual se quita el sabor amargo; este paso es esencial ya que se remueven alcaloides (Bermejo \& León, 1994). Durante este proceso, la composición del grano seco, se altera, se puede dar una pérdida de macronutrientes (carbohidratos y grasas) y micronutrientes (minerales) (Carvajal-Larenas et al., 2014); los granos de soya no atraviesan este proceso para ser comestibles.

Además, durante la fase de precipitación, la concentración de $\mathrm{HCl}$ pudo haber sido demasiado alta y pudo haber causado la desnaturalización de proteínas. Para optimizar la hidrólisis de proteínas, una extracción fraccionada debería ser considerada. El incremento gradual de la concentración del ácido permitiría un aislamiento con mínimo daño estructural de las proteínas (Sun et al., 2004).

De los aminoácidos identificados por CCF, el ácido glutámico y los BCAA, promueven la función inmune y la capacidad de reparación muscular.

El ácido glutámico no está directamente relacionado con el sistema inmune, su amida, la glutamina, sí. La glutamina se sintetiza a partir del amoniaco y el ácido glutámico por la enzima glutamina sintetasa; la mayor producción de glutamina ocurre en el sistema músculo esquelético. 
Dentro del sistema inmune, la glutamina potencia la proliferación de células $\mathrm{T}$ y de citosinas, que ayudan a regular la respuesta inmune (Newsholme et al., 2003). Después de la actividad física extenuante, los atletas experimentan un descenso en los niveles de glutamina. La reducción puede llevar a infecciones leves; es por esta razón que los expertos recomiendan un suplemento de glutamina para reducir las posibilidades de infección (Ehrlich, 2013). Durante ejercicio físico prolongado, los niveles de amoniaco en la sangre se elevan y esto es una causa de fatiga. La hiperamonemia inducida por el ejer- cicio es un problema común entre los deportistas, se sugiere suplementación de glutamina para reducir los niveles de amoniaco, prevenir la fatiga y potenciar el desempeño (Carvalho-Peixoto, Alves y Cameron, 2007).

Igualmente, el cromatograma (Figura 1) muestra la presencia de BCAA (leucina, isoleucina, valina). Estos aminoácidos están presentes en las proteínas del músculo esquelético (14-18\%), el consumo de BCAA es importante ya que la masa muscular representa el $40 \%$ del peso corporal total (Shimomura et al., 2006).

\section{CONCLUSIONES}

El análisis proximal demostró que la muestra tiene un contenido proteico de $67,25 \%$. Sin embargo, para obtener un contenido proteico más alto se debería probar otro método de aislamiento más apto. De acuerdo con el análisis de CCF, la mayoría de aminoácidos esenciales se encuentran presentes en el aislado proteico. Los aminoácidos de cadena ramificada y el ácido glutámico fueron identificados, lo que hace que el aislado sea un candidato para el desarrollo de suplementos nutricionales para deportistas. No obstante, es necesaria una cuantificación para tener un mejor entendimiento del valor nutricional que puede aportar el aislado proteico de chocho. 


\section{LISTA DE REFERENCIAS}

AOAC. (2011a). Method 925.10: Solids (Total) and Loss on Drying (Moisture) in Flour. In Official Methods of Analysis of AOAC International (18th ed., p. 1). Gaithersburg.

AOAC. (2011b). Method 2001.11 Protein (Crude) in Animal Feed, Forage (Plant Tissue), Grain, and Oilseed. In Official Methods of Analysis of AOAC International (18th ed., pp. 34-37). Gaithersburg: AOAC International.

AOAC. (2011c). Methods 2003.05 Crude Fat in Feeds, Cereal Grains, and Forages. In Official Methods of Analysis of AOAC International (18th ed., pp. 41-43). Gaithersburg.

AOAC. (2011d). Method 923.03 Ash of Flour. In Official Methods of Analysis of AOAC International (18th ed., p. 2). Gaithersburg.

Bermejo, J. y León, J. (1994). Neglected crops: 1492 from a different perspective. Roma: Food and Agriculture Organization of the United.

Bluebonnet Nutrition Corporation. (2015). 100\% Natural Whey Protein Isolate Powder, Sugar Land, TX, USA.

Børsheim, E., Tipton, K.D., Wolf, S.E. y Wolfe, R.R. (2002). Essential amino acids and muscle protein recovery from resistance exercise. American Journal of Physiology. Rndocrinology and Metabolism, 283(4), E648-57.

doi:10.1152/ajpendo.00466.2001

Carvajal-Larenas, F.E., Van Boekel, M.J.A.S., Koziol, M., Nout, M.J.R. y Linnemann, A.R. (2014). Effect of Processing on the Diffusion of Alkaloids and Quality of Lupinus mutabilis Sweet. Journal of Food Processing and Preservation, 38(4), 1461-1471. doi:10.1111/jfpp. 12105

Carvalho-Peixoto, J., Alves, R.C. y Cameron, L.C. (2007). Glutamine and carbohydrate supplements reduce ammonemia increase during endurance field exercise. Applied Physiology, Nutrition, and Metabolism, 32(6), 1186-1190.

doi:10.1139/H07-091 
Ehrlich, S.D. (2013). Glutamine. http://umm.edu/health/medical/altmed/supplement/glutamine

FAO. (2003a). Weighing the GMO arguments: against. http://www.fao.org/english/newsroom/focus/2003/gmo8.htm

FAO. (2003b). Food energy - methods of analysis and conversion factors. Rome: Food and Agriculture Organization Of The United Nations.

Farrell, P.A., Joyner, M.J. y Caiozzo, V. (2012). Advanced Exercise Physiology (Second Ed.). Baltimore: American College of Sports Medicine.

Growing Naturals. (2015). Pea Protein. Culver City, CA, USA

Haer, F.C. (1969). An Introduction to Chromatography on Impregnated Glass Fiber. Ann Arbor: Ann Arbor Science Publishers, Inc.

Horton, D. (2014). Investigación Colaborativa de Granos Andinos en Ecuador. Quito: Fundación McKnight \& Instituto Nacional Autónomo de Investigaciones Agropecuarias.

IBM. (2012). IBM SPSS Statistics.

Jacobsen, S. y Mujica, A. (2006). El Tarwi (Lupinus mutabilis Sweet.) y sus parientes silvestres. In Botánica Económica de los Andes Centrales, 458-482.

Jacobsen, S. y Sherwood, S. (2002). La producción de chocho y amaranto. In Cultivo de granos andinos en Ecuador (pp. 34-36). Quito: Abya Ayala.

Jaramillo Galarza, M.G. (2005). Determinación de Plomo en Chocho que se expende en la vía pública por Espectrofotometría de Absorción Atómica. Pontificia Universidad Católica del Ecuador.

Kalman, D. (2014). Amino Acid Composition of an Organic Brown Rice Protein Concentrate and Isolate Compared to Soy and Whey Concentrates and Isolates. Foods, 3(3), 394-402.

doi:10.3390/foods3030394 
Lusas, E. y Riaz, M. (1995). Soy protein products: processing and use. The Journal of Nutrition, 125(3 Suppl), $573-580$.

Newsholme, P. Lima, M.M.R., Procopio, J., Pithon-Curi, T.C., Doi, S.Q., Bazotte, R.B. y Curi, R. (2003). Glutamine and glutamate as vital metabolites. Brazilian Journal of Medical and Biological Research, 36(2), 153-163.

NOW Foods. (2015). Soy Protein Isolate. Bloomingdale, IL, USA

Peralta, E.N., Mazón, Á., Murillo, M., Rivera, D., Rodríguez, L. y Lomas, C.M. (2012). Manual agrícola de granos andinos: Chocho, Quinua, Amaranto y Ataco. Cultivos, variedades y costos de producción. Publicación Miscelánea, (69).

Shimomura, Y., Yamamoto, Y., Bajotto, G., Sato, J., Murakami, T., Shimomura, N., ... Mawatari, K. (2006). Nutraceutical effects of branched-chain amino acids on skeletal muscle. The Journal of Nutrition, (1), 529-532.

Staneck, J. (1974). Simplified Approach to Identification of Aerobic Actinomycetes by Thin-Layer Chromatography. Applied Microbiology, 28(2), 226-231.

Sun, J. X., Sun, X.F., Sun, R.C. y Su, Y.Q. (2004). Fractional extraction and structural characterization of sugarcane bagasse hemicelluloses. Carbohydrate Polymers, 56(2), 195-204. doi:10.1016/j.carbpol.2004.02.002

Villacrés, E., Rubio, A., Egas, L. y Segovia, G. (2006). Usos alternativos del chocho. INIAP, 1-19. 